\title{
Letter
}

\section{Densification Kinetics of Multi-Doped Zirconia Ceramic Body with Organic Coating Powders}

\author{
Yonggang Hoo ${ }^{1,2, *}$ Yusheng Shi ${ }^{1}$ and Wenzhong $\mathrm{Lu}^{2}$ \\ 1 State Key Laboratory of Materials Processing and Die \& Mould Technology, School of Materials Science and \\ Engineering, Huazhong University of Science and Technology, Wuhan 430074, China; \\ shiyusheng@hust.edu.cn \\ 2 School of Optical and Electronic Information, Huazhong University of Science and Technology, Wuhan \\ 430074, China; lwz@mail.hust.edu.cn \\ * Correspondence: yongganghu@hust.edu.cn; Tel: +86(0)13554328440.
}

\begin{abstract}
This work for the first time investigated the densification of multi-doping zirconia ceramic body with organic coating powders for solid electrolyte of solid oxide fuel cells via online imaging technology. The densification results show the initial stage plays a key role in the sintering. It can be found the covered organic PVA (polyvinyl acetate) supplies a potential kinetics to the initial densification during sintering. As a result, a kinetic function of densification in the initial stage was suggested. Furthermore, a novel sintering model with six sub-stages is developed for polycrystalline zirconia ceramics. The findings would be a valuable reference for predicting final temperature of sintering, the equivalent strain during the sintering process, as well as optimizing the densification behavior.
\end{abstract}

Keywords: online imaging analysis; polycrystalline zirconia; densification kinetics

\section{Introduction}

YSZ-based (yttria stabilized zirconia) solid electrolytes have been used for solid oxide fuel cells (SOFC), but the high grain boundary resistance for oxygen ion transport and weak refractory $[1,2]$ constrain its further industrial application. Magnesia and yttria bi-doping zirconia ceramics, due to the lower-costs raw materials, are recognized as fascinating potential solid electrolytes for moderate temperature application. However, with the increasing of magnesia element, the sintering temperature reaches to $1750{ }^{\circ} \mathrm{C}$ even over $1800{ }^{\circ} \mathrm{C}$ for several tens hours. As the most important process in ceramic industries, the higher temperature of sintering and the longer time for holding, the more it costs. Therefore, a clear understanding of sintering plays a key role in fabricating the high performance zirconia solid electrolytes inexpensively.

In recent years, more scientists focus on the densification mechanisms in order to control the density and microstructure for improving the properties. Hansen [3] suggested a combined sintering mode, and Johnson [4] developed the master sintering curve method based on Hansen's model. The master sintering curve was independent on the heating rate which could predict the densification of sintering and the final density for the multi-phase system, but the calculation is very complicated. The sintering of materials with voids, assumed elastic materials, had been described for the phenomenological model of sintering [5-8]. Rahaman and De Jonghe [9] introduced the bulk viscosity and creep effects in the sintering of glass powder to study the densification kinetics. As a function of porosity, Beere [10] determined that the sintering force was an inversely-proportional relationship to grain size, and the densification mechanisms of bulk and grain boundary diffusion were obtained. Scherer [11] expressed an explicit relationship of effective viscosity and volume shrinkage rate for linear-viscous models. Rahaman [12] demonstrated the densification of compact powder bodies without consideration of the surface tension effects. McMeeking [13, 14] noted that diffusion induced creep was a controlled step in the first stage of sintering. Cocks [15] introduced 
capillary stresses to describe the initial stage while the surface energy was absent. However, to our best knowledge, no effort has been made to consider the effect of organic matter addition on the densification in the first stage of sintering. As a result, a clear overall understanding of sintering for multi-doped zirconia system is not reported until now.

In the present work, the densification of $\mathrm{Y}_{2} \mathrm{O}_{3}-\mathrm{MgO}-\mathrm{Al}_{2} \mathrm{O}_{3}-\mathrm{CaO}$ multi-doping zirconia ceramics with organic coating powders are investigated by an online imaging method to obtain the terminal temperature of co-sintering and the densification kinetics is discussed. This work, for the first time, reports a densification model with six sub-stages for partially stabilized zirconia and suggests a kinetic function of densification in the initial sintering stage.

\section{Experimental Methods}

\subsection{Raw Materials and Specimen Preparation}

The raw powders were supplied by Sansai Company (Yixing, China). SP1 and SP2 were pressed into cubes, respectively, where SP1 is made by powders of $\mathrm{Y}_{2} \mathrm{O}_{3}-\mathrm{ZrO}_{2}: \mathrm{MgO}-\mathrm{ZrO}_{2}: \mathrm{CaO}_{-} \mathrm{ZrO}_{2}$ : $\mathrm{Al}_{2} \mathrm{O}_{3}-\mathrm{ZrO}_{2}=60: 18: 15: 7$ (wt \%), SP2 is made by the same powders but uncoated with PVA solution as a contrast. The particle size distribution is measured by an SA-CP3 type particle size analyzer (Japan) as shown in Fig. 1. The preparation of SP1 specimen was mainly following the two features: Firstly, a particle assembly was carried out by particle bonding technology based on mechanical mixing method (PBT-MMM) to make spheroidal composite particles coated with PVA solution, which
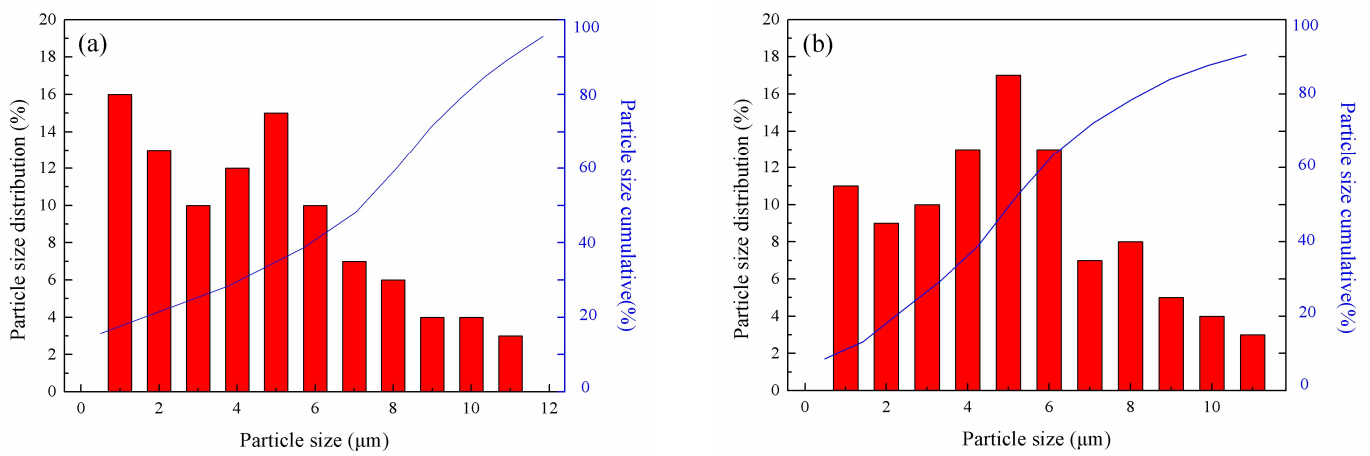

Fig.1 The particle size distribution of SP1 and SP2 samples (shown in Fig. 1(a) and (b), respectively).

can achieve particle bonding directly in dry conditions even at room temperature. Second, the pressed compacts were conducted by Powder Injection Molding with dry powders mentioned above under $80 \mathrm{MPa}$. The green bodies were then sintered with online imaging Instrument (SJY-2, Xiangtan, China) in Ar atmosphere with a $10^{\circ} \mathrm{C} / \mathrm{min}$ heat-up rate to $1650^{\circ} \mathrm{C}$.

\subsection{Data Acquisition and Materials Characteristics}

For seeking the densification mechanisms, the photographs were captured every $100^{\circ} \mathrm{C}$ before $1200{ }^{\circ} \mathrm{C}$, every $20^{\circ} \mathrm{C}$ before $1500{ }^{\circ} \mathrm{C}$, and every $15^{\circ} \mathrm{C}$ after $1500^{\circ} \mathrm{C}$ during sintering, respectively. The exact in-situ measurement of the dimensional change was obtained by Image-Pro software with an accuracy of $2 \mu \mathrm{m}$. Based on these data, the shrinkage values in $x, y$ directions varied with temperature were determined. The terminal density of specimen after sintering was obtained by Archimedes principle. The surface microstructures and fracture diagrams of SP1 and SP2 specimens were observed by scanning electron microscope (Quanta 200, FEI). 


\section{Results and Discussion}

\subsection{Initial Particle Size Distribution and the Microstructures after Sintering}

As shown in Fig.1 (a) and (b), each of the particle size distribution of SP1 and SP2 is continuous distribution. But the gradients are not similar to each other; the former is a gentle slope following an abrupt slope, and the latter is a steep slope following a gentle section. The particle size distribution of SP1 (shown in Fig. 1(a)) reveals that the particle size is not uniform, but the powder composition is favorable. It can be seen from Fig. 2, the average grain size after sintering of SP1 and SP2 are both not over $10 \mu \mathrm{m}$, which not occurring an additional grain coarsening. The relative density of SP1 is higher than SP2 that are $98.6 \%$ and $96.7 \%\left(\varrho 1=5.78\right.$ and $\mathrm{Q} 2=5.67 \mathrm{~g} / \mathrm{cm}^{3}$ ) which with the benefit of the more number of smaller powders. As shown in Fig. 2a, the tri-junction boundary is straight and the cavity is invisible among grains, which indicates that the sintering was perfect according to the traditional sintering theory.
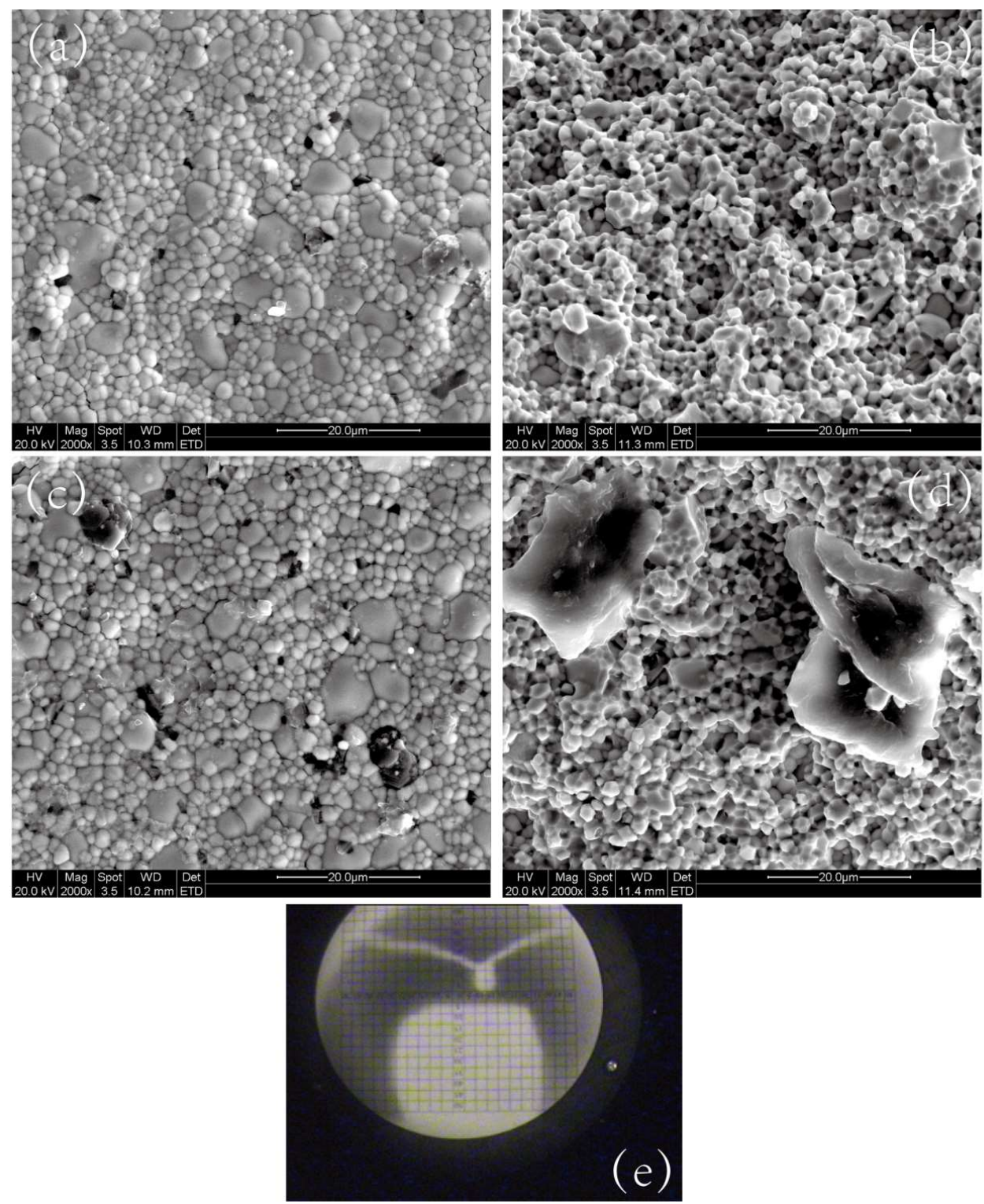

Fig. 2 Typical microstructures and fracture diagrams of SP1 and SP2 after sintering (a, b is the microstructure of SP1, c, d is that of SP2, e is the typical online image at elevated temperature). 


\subsection{Densification Mechanisms}

Fig.3 (a) and (b) show the densification tendency of SP1 and SP2 in x- and y-directions when sintering. It can be seen from the results shown in Fig. 3(a), with increasing of temperature, there shows a linear densification in $\mathrm{x}$-direction before $1200^{\circ} \mathrm{C}$ and a sharp increase of densification rate after $1200^{\circ} \mathrm{C}$. A densification platform is occurring around $1500{ }^{\circ} \mathrm{C}$, which indicates the pausing of densification. With the temperature increasing to $1625^{\circ} \mathrm{C}$, the shrinkage value declines to zero again defined as the sintering end-point. There also illustrates linear densification in $\mathrm{y}$-direction before $1200{ }^{\circ} \mathrm{C}$ and shows a sharp increase of densification rate after $1200{ }^{\circ} \mathrm{C}$. However, the densification rate is higher than that of in the $\mathrm{x}$-direction before $1400{ }^{\circ} \mathrm{C}$, and the earlier densification in the $\mathrm{y}$-direction is occurring comparison with that of in the $\mathrm{x}$-direction.

From Fig. 3b, it shows that the densification of unprocessed SP2 is very different from that of $\mathrm{SP1}$. The densification rate in $\mathrm{y}$-direction is smaller than that of $\mathrm{x}$-direction before $1250{ }^{\circ} \mathrm{C}$. The densification platform, indicates the stopping of densification, is occurring at $1500{ }^{\circ} \mathrm{C}$ later than that of SP1; and the second one in x-direction is not observed before $1650{ }^{\circ} \mathrm{C}$. On the evidence of the experimental result shown in Fig. 2d, it is not complete densification. According to sintering theory, a densification platform indicates a neck forming or mass transport between the grain boundaries, which needs more Gibbs energy as sintering force.

As shown in Fig. 3, the porous phase is removed slowly with the increasing of temperature before $1200{ }^{\circ} \mathrm{C}$; the densification or the arrangement of particles is occurring in the range of $1200-1500^{\circ} \mathrm{C}$. In this stage, the adjacent particles are connected and the pores are filled through mass transport. After $1500{ }^{\circ} \mathrm{C}$, the densification rate falls off gradually until stopping again. Combining the results shown in Fig. $2 b$, it can be concluded that, for the polycrystalline ceramics, honeycomb grain boundary alongside the straight grain boundary illustrates the dominant mechanisms in the final stage of sintering is volume diffusion accompanied with an elastic flow but plastic deformation (called high temperature creep deformation).
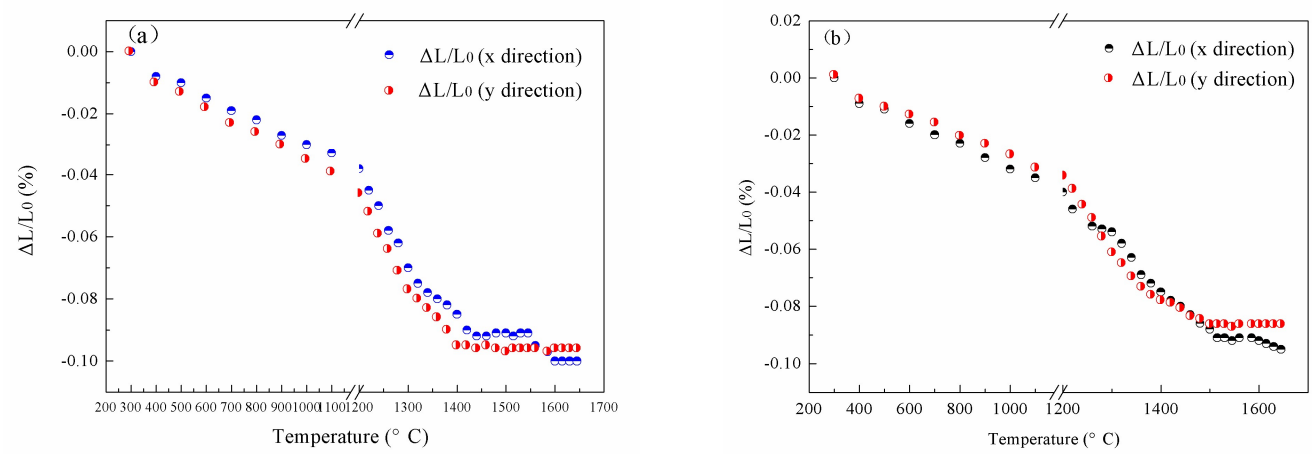

Fig. 3 The main sintering curves of SP1 (a) and SP2 (b).

\subsection{Discussion}

The densification mechanisms, we suggested, could be divided into two types: 1) the chemical potential induced; 2) the spatial force induced. For polycrystalline ceramics, the bulk diffusion was always ignored in traditional sintering theory, although the stress had been considered to describe grain boundary diffusion. The mechanisms reported by Ashby [16,17] and Exner [18] in last decades showed there are surface diffusion, vapor-phase transport, lattice diffusion, and grain boundary diffusion or their intersection. In this study, the physical equilibrium category is verified to be a meta-scopic level of volume and particle shrinkage. The mass transport through particles is considered as a global concept.

This useful simplification supplies significant insights into the densification. According to traditional sintering theory, the grain boundary will be straight in the final stage of sintering, which cannot give a clear interpretation for partially stabilized zirconia ceramics such polycrystalline and multi-phase material. Although Thouless [19] suggested a creep mechanism for thin films based on surface and grain boundary diffusion, the effect of physical behavior discrepancy was not been 
considered in that specific work. Ashby [20] published a creep function to describe the densification under pressure sintering, which had considered the material parameters. The power-law creep is:

$$
\frac{\sigma}{\sigma_{0}}=\mathrm{A}\left[\frac{\dot{\varepsilon}}{\dot{\varepsilon}_{0}}\right]^{\mathrm{m}}
$$

where $\mathrm{A}$ and $\mathrm{m}$ is the material parameters, $\sigma$ and $\varepsilon$ is the equivalent stress and equivalent strain. The spatial force balance is a key factor to affect the final densification of ceramics, especially for the polycrystalline material.

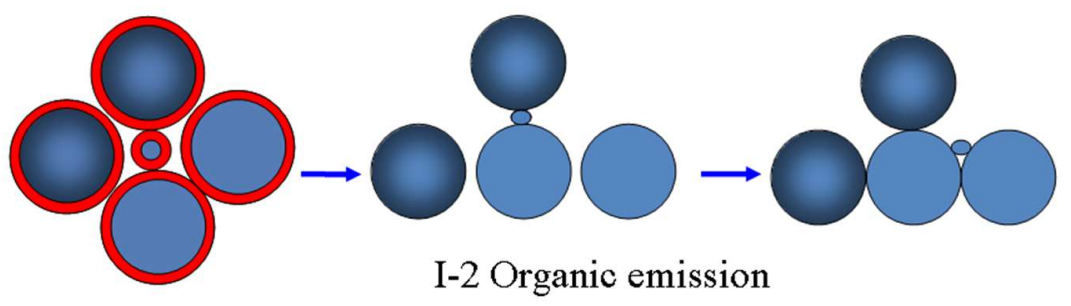

I-1 PVA coating compaction

II-1 Sub-powder restoration

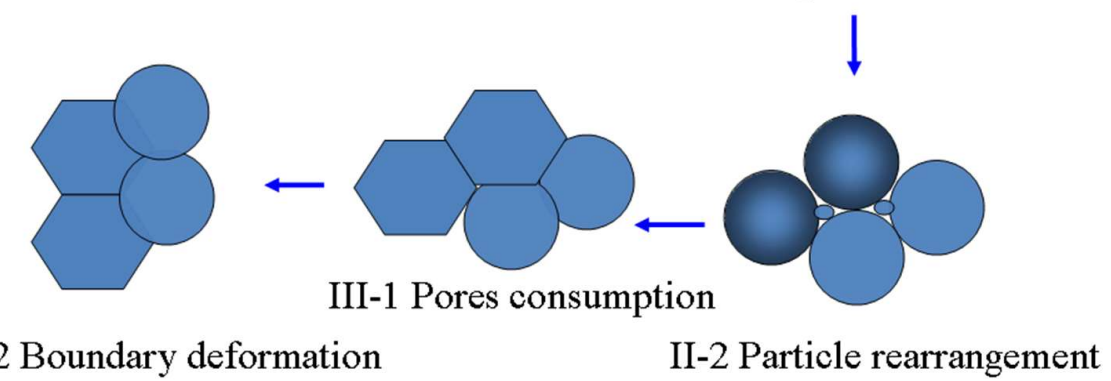

\section{III-2 Boundary deformation II-2 Particle rearrangement}

Fig.4 The schematic representation of sintering model of polycrystalline zirconia with six stages $(1$, PVA coating powders compaction, 2, organic emission at low temperature, 3, sub-powders restoration, 4, Particles rearrangement, 5, Pores consumption at high temperature, 6, grain boundaries deformation.)

From the main sintering curves (shown in Fig. 3), the densification rate associated with unequal distance among particles will be described as three stages: initial, intermediate and final, which can be divided into six sub-stages, to characterize the whole sintering period. The six sub-stages, to describe the densification schematically, are presented in Fig. 4. In the first sub-initial stage (I-1), with the PVA coating of SP1, the elastic flow of PVA increases the densification rate in y-direction until the volatile component burnt. After the organic being combusted that leaving a gas emission passage, the second sub-initial stage (I-2) shows the slower densification rate in the x-direction, which is beneficial to further densification in the y-direction. With the gas discharging, the pores adjacent to grains are slowly closed. In the first sub-intermediate stage (II-1), because of the high activation energy of processed powders by a mechanical method, the surface energy decreases with the particles rearrangement or particles restoration through bonding tiny powder to a small one. The pores located near the tiny powders are closed while the bonding continues in the second sub-intermediate stage (II-2), and the further particles rearrangement is continued. The significant change in the intermediate stage is the secondary scale powders combined with others. The densification rate in this stage is greatly higher than that of in the initial stage, but the total shrinkages are similar to that of in the initial stage. The appearance of the first shrinkage platform is the start of the final stage. During the first sub-final stage (III-1), the grain boundary migration and coalescence continues when the separate pores were consumed. The bonded grains were then becoming one with the disappearance of grain boundary which causes the densification rate near to zero. This phenomenon indicates that the densification is nearly completed according to 
conventional sintering theory. Differently, in this study, the further densification following the densification platform takes place in the second sub-final stage (III-2). From the results shown in Fig. $2 b$, the honeycomb fracture indicates that the boundary deformation was achieved in this stage, owing to the creep densification mechanism.

Due to no shape change in this free sintering, taking the sintering stress and shear modulus into consideration, the shrinkage rate could be expressed as:

$$
-\mathrm{P}_{\mathrm{L}} \varphi \gamma=\tau \psi \mathrm{e}
$$

where $P_{L}$ is the capillary stresses, $e$ is the shrinkage rate, $\psi$ and $\varphi$ is a function of the porosity, respectively, $\gamma$ is the average strain rate tensor, and $\tau$ is the average yield stress. If the phase transformation is considered as a factor of deformation, the thermo-dynamical coupled model should be introduced, which had been developed in the intermediate stage by Olevsky et al. [21].

\section{Conclusions}

A sintering model for partially stabilized zirconia has been developed by online imaging analysis. From the results, the densification rate of the initial stage of sintering has a potential influence on the final densification, which can be improved by coating PVA. The main conclusions are summarized as:

(1) The densification mechanisms of polycrystalline zirconia under free sintering are identified. Six sub-stages are presented to describe the densification. Being different with conventional sintering theory, a creep densification accompanied with the boundary deformation takes place to form the honeycomb grains in the final stage of sintering.

(2) With the online imaging analysis, the study of densification curve makes the prediction of the final temperature of sintering to be possible. It can also provide a valuable reference for optimizing the densification and the equivalent strain during the sintering process.

Acknowledgments: This work was partially supported by the National Key Foundation Research plan of China (61362). Thanks are kindly expressed to Prof. Jianzhong Xiao for his support to finish the experiments. The authors are grateful for the Analysis and Testing Center of Huazhong University of Science and Technology for SEM tests, as well as Dr. Qingqing Yang and Dr. Huatang Tan for particle distribution testing.

\section{References}

1. Zhang TS, Zeng ZQ, Huang HT, Hing P, Kinler J. Effect of alumina addition on the electrical and mechanical properties of $\mathrm{Ce}_{0.8} \mathrm{Gd}_{0.2} \mathrm{O}_{2-\delta}$ ceramics. Mater Lett. 2002;57(1):124-129.

2. Lowrie FL, Rawlings RD. Room and high temperature failure mechanisms in solid oxide fuel cell electrolytes. J Eur Ceram Soc. 2000;20(6):751-760.

3. Hansen JD, Rusin RP, Teng MH, Johnson DL. Combined-stage sintering model. J Am Ceram Soc. 1992;75(5):1129-1135.

4. Su H, Johnson DL. Sintering of alumina in microwave-induced oxygen plasma. J Am Ceram Soc. 1996;79(12):3199-3210.

5. Venkatachari KR, Raj R. Shear deformation and densification of powder compacts. J Am Ceram Soc. 1986;69(6):499-506.

6. Jagota A, Mikeska KR, Bordia RK. Isotropic constitutive model for sintering particle packings. J Am Ceram Soc. 1990;73(8):2266-2273.

7. Riedel H, Zipse H, Svoboda J. Equilibrium pore surfaces, sintering stresses and constitutive equations for the intermediate and late stages of sintering: Part II. Diffusional densification and creep. Acta Metall Mater. 1994;42(2):445.

8. Rahaman MN, De Jonghe LC, Scherer GW, Brook RJ. Creep and densification during sintering of glass powder compacts. J Am Ceram Soc. 1987;70(10):766-774.

9. Rahaman MN, De Jonghe LC. Sintering of spherical glass powder under a uniaxial stress. J Am Ceram Soc. 1990;73(3):707-712.

10. Beere W. The second stage sintering kinetics of powder compacts. Acta Metall Mater. 1975;23(1): 139. 
11. Bordia RK, Scherer GW. Overview no. 70 on constrained sintering: II. Comparison of constitutive models. Acta Metall Mater. 1988;36(9):2399.

12. De Jonghe LC, Rahaman MN. Sintering stress of homogeneous and heterogeneous powder compacts. Acta Metall Mater. 1988;36(1):223.

13. McMeeking RM, Kuhn LT. A diffusional creep law for powder compacts. Acta Metall Mater. 1992;40(5):961.

14. Bouvard D, McMeeking RM. Deformation of interparticle necks by diffusion-controlled creep. J Am Ceram Soc. 1996;79(3):666-672.

15. Cocks ACF, Aparicio ND. Diffusional creep and sintering - the application of bounding theorems. Acta Metall Mater. 1995;43(2):731.

16. Ashby MF. A first report on sintering diagrams. Acta Metall. 1974;22(3):275.

17. Swinkels FB, Ashby MF. Overview 11- $2^{\text {nd }}$ report on sintering diagrams. Acta Metall. 1981;29(2):259.

18. Exner HE, Arzt E. Sintering processes. In: Cahn RW, Haassen P, editors. Physical Metallurgy. 3rd ed. Amsterdam: Elsevier; 1983.

19. Thouless MD. Effect of surface diffusion on the creep of thin films and sintered arrays of particles. Acta Metall Mater. 1993;41(4):1057.

20. Wilkinson DS, Ashby MF. Pressure sintering by power law creep. Acta Metall. 1975;23(11):1277-1285.

21. Olevsky E, Skorohod V, Petzow G. Densification by sintering incorporating phase transformations. Scripta Mater. 1997;37(5):635-643. 